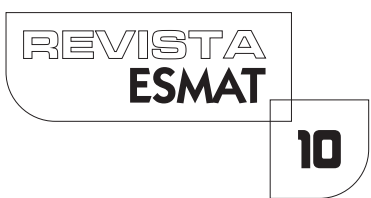

\title{
ABUSO DO PODER ECONÔMICO NA PROPAGANDA ELEITORAL ANTECIPADA
}

\author{
ABUSE OF ECONOMIC POWER IN THE EARLY ELECTIONEERING
}

Afonso Filho Pereira Ramos da Silva

Analista técnico processual no Ministério da Agricultura Pecuária e Abastecimento Superintendência Federal do Tocantins. Advogado. Pós-Graduando em Direito Público pelo Centro Universitário Luterano de Palmas. E-mail:afonsogo23@hotmail.com

Carlos Victor Almeida Cardoso Júnior

Chefe da Assessoria Jurídica da Fundação Redesat do Estado do Tocantins. Professor do Curso de Direito do Centro Universitário Luterano de Palmas e Advogado militante. Especialista em Políticas Públicas e Gestão Estratégica da Saúde pela Universidade Federal do Tocantins. Email:jr.cam@uol.com.br

\section{RESUMO}

presente artigo aponta duas das formas ilícitas empregadas na propaganda eleitoral, uma que é a veiculação antes do prazo legal e a outra o abuso do poder econômico. Casos envolvendo interferências do poder econômico nas campanhas eleitorais com o objetivo de interferir no resultado do pleito são cada vez mais comuns nos noticiários. A Lei das Eleições (Lei n 9.504, de 1997) veda essa prática; contudo, esse fator não intimida os candidatos, partidos e suas coligações. De acordo com a alteração da referida Lei pela Lei $n^{\circ}$ 13.165, de 29 de setembro de 2015, o prazo legal para realização de propaganda eleitoral, agora é somente após o dia I 5 de agosto do ano da eleição. No entanto, muitos candidatos infringem essa regra, estimulados pelas multas irrisórias ante os elevados recursos disponibilizados. Dessa forma, o intuito deste trabalho é demonstrar essas duas formas ilícitas empregadas na propaganda eleitoral extemporânea e como se evidencia o abuso de poder econômico na propaganda eleitoral antecipada, por meio de levantamento bibliográfico, estudo de textos legais, doutrinas e entendimentos jurisprudenciais mais recentes sobre o assunto. Conclui-se que a veiculação da propaganda eleitoral deve ocorrer apenas no prazo estipulado pela legislação em vigor, e o poder econômico deve permanecer neutro, para que haja 
equilíbrio entre os candidatos, atendendo, assim, os princípios fundamentais que regem o direito eleitoral.

PALAVRAS-CHAVE: Direito eleitoral brasileiro. Propaganda eleitoral. Abuso do poder econômico.

\section{ABSTRACT}

This article discusses out one of the forms used in illegal electioneering, which is serving before the legal deadline and the abuse of economic power. Cases involving interference of economic power in election campaigns in order to interfere in the election result are increasingly common in the legal environment. The Election Law (Law $n^{\circ}$. 9.504, of 1997) seal this practice; however, this factor does not deter the candidates, parties and their coalitions. According to the amendments to that law by Law no. I 3, 165 of september 29, 20 I 5, the legal deadline for electoral propaganda, now it is only after the 15 th of the election year in august, however, many candidates violate that rule stimulated by fines derisory before the high available resources. Thus, the aim of this work is to demonstrate the ways in which it highlights the abuse of economic power in advance electoral propaganda by means of literature, study of legal texts, doctrines and latest jurisprudential understandings on the subject. It is concluded that the placement of election propaganda should occur only within the period stipulated by the legislation and the economic power must remain neutral so that there is balance between the candidates, and meets the fundamental principles governing the electoral law.

KEYWORDS: Brazilian electoral law. Electioneering. Abuse of economic power.eleitoral brasileiro. Propaganda eleitoral. Abuso do poder econômico.

\section{INTRODUÇÃO}

A abordagem do tema está relacionada à necessidade de demonstrar a importância do estudo na ciência do direito eleitoral na sociedade contemporânea. $\bigcirc$ direito eleitoral no Brasil é encarregado de regulamentar os direitos políticos dos cidadãos e o processo eleitoral.

No Brasil, a Constituição Federal, de 1988, descreve que todo poder emana do povo. No entanto, conhece-se que no regime democrático representativo, em regra, o povo não exerce o poder diretamente, mas sim por intermédio de representantes eleitos diretamente pela população por meio do voto. 
Na mídia nacional, são veiculados frequentemente casos de interferências do poder econômico nas campanhas eleitorais com o objetivo de interferir no resultado do pleito. A Lei das Eleições (Lei n 9.504, de 1997) veda essa prática; contudo, esse fator não intimida os candidatos, os partidos e suas coligações a praticarem tal conduta.

É comum o entrelaçamento das práticas abusivas, numa imbricação de interesses em que se revela a utilização do poder político e do poder econômico para a distribuição de benesses de toda ordem às vésperas do pleito, como, por exemplo, o financiamento indireto de propaganda eleitoral, a utilização dos programas sociais e da máquina administrativa, ferindo, assim, os princípios basilares do jogo democrático.

A propaganda eleitoral é um instrumento utilizado por candidatos a cargos eletivos para divulgação de suas propostas para a população. No entanto, muitas vezes a propaganda é desrespeitada por vários candidatos que adotam práticas configuradas como campanha eleitoral antes do prazo estabelecido pela legislação.

A Lei n 9.504, de 1997, em seus artigos 36 a 57, aliada às resoluções editadas pelo Tribunal Superior Eleitoral (TSE) definem as regras a serem aplicadas nas eleições, fixando a orientação jurisprudencial sedimentada no âmbito da Justiça Eleitoral. A lei eleitoral impõe regras para a elaboração e veiculação da propaganda eleitoral no intuito de assegurar a isonomia de oportunidades aos candidatos.

As limitações impostas à propaganda contidas na Lei n 9.504, de 1997, relativizam o direito de liberdade de expressão dos candidatos e garantem a igualdade de tratamento entre estes, os partidos e as coligações (ARAGÃO, 2007, p. I 6).

A propaganda eleitoral antecipada não é tema recente, porém é pouco debatida entre os doutrinadores, por isso, a importância de sua abordagem e discussão sobre seus principais pontos; assim há necessidade de uma análise conjunta com o posicionamento do Tribunal Superior Eleitoral (TSE) a respeito da propaganda eleitoral extemporânea.

Para aprofundamento dessa discussão, realizou-se amplo estudo bibliográfico, a partir de análise de textos legais, doutrinas e entendimentos jurisprudenciais mais recentes sobre o assunto.

\section{DIREITO ELEITORAL BRASILEIRO}

\section{I Contextualização sobre Direito Eleitoral}

direito eleitoral é um ramo do direito público que objetiva estudar o sistema eleitoral e suas normas, os institutos e também os procedimentos reguladores dos direitos políticos, haja vista comportar grande relação com assuntos ligados ao interesse do Estado. $O$ conceito de direito eleitoral, todavia, não é unânime nos estudos doutrinários. 
Pinho (2010) destaca que o direito eleitoral é o campo do direito que tem por finalidade disciplinar as regras que determinam a forma, o modelo e as características da representatividade política tão indispensável para a consolidação do Estado Democrático de Direito.

O direito eleitoral se consolida mais por suas características peculiares do que por descender do próprio direito constitucional, pertencendo este ao ramo do direito público (CÂNDIDO, 1996).

Para Gomes (20 I I), o direito eleitoral normatiza o exercício do sufrágio com vista à concretização da soberania popular.

Gomes (2012) complementa a conceituação do ramo ao dizer que o direito eleitoral disciplina a criação dos partidos políticos, o ingresso dos cidadãos no corpo eleitoral para a fruição dos direitos políticos, o registro de candidaturas, a propaganda eleitoral, o processo e a investidura no mandato eletivo.

De acordo com alteração dada ao artigo 36 da Lei n 9.504, de 1997, pela Lei nº 13. I 65, de 29 de setembro de 20 I5, podemos notar que a propaganda eleitoral agora passou a ser permitida somente após o dia 15 de agosto do ano da eleição, e não mais 5 de julho como previsto anteriormente. A regra geral agora é nunca realizar pedido explícito de votos antes do dia 16 de agosto do ano da eleição.

Dessa forma, a propaganda eleitoral realizada até o dia I 5 de agosto do ano da eleição, com exceção da propaganda intrapartidária, caberá à interposição da representação eleitoral contra o pré-candidato; mas se este respeitar o prazo legal estará bem prevenido contra as eventuais acusações de prática de propaganda eleitoral extemporânea.

Propaganda intrapartidária, é aquela permitida antes do dia I 5 de agosto do ano da eleição para que os políticos efetuem-na internamente no âmbito adstrito das convenções para persuadir os correligionários a eleger o candidato que concorrerá à eleição e também definir eventuais coligações.

Segundo o TSE, ao candidato que pretende concorrer nas eleições, a lei permite que ele possa fazer propaganda intrapartidária, nos I 5 dias anteriores aos da convenção do partido, com o objetivo de promover a indicação de seu nome. Pode até mesmo colocar faixas e cartazes em local próximo ao da convenção, com mensagem dirigida aos convencionais, sendo proibido, no entanto, o uso de rádio ou televisão e de outdoor. As regras determinam que essa propaganda deva ser imediatamente retirada logo após o evento.

As convenções dos partidos para deliberar sobre coligações e escolha de candidatos a prefeito, vice-prefeito e a vereador devem ocorrer de 20 de julho a 5 de agosto do ano eleitoral.

Nas alterações da propaganda eleitoral promovidas pela Lei $n^{\circ} 13.165$, de 20।5, a realizada antes do prazo acima mencionado, denominada de propaganda antecipada, é punida com a aplicação de multa que varia de $R \$ 5.000,00$ (cinco mil reais) a $R \$$ 25.000,00 (vinte e cinco mil reais). Todavia, pelo novo texto da lei não se consideram 
mais propaganda eleitoral antecipada a menção à pretensa candidatura, a exaltação das qualidades pessoais dos pré-candidatos e os seguintes atos que poderão ter cobertura dos meios de comunicação social, até mesmo via internet (art.36-A, caput, da Lei n 9.504, de 1997).

A Lei n 12.034, de 2009, ainda inseriu os artigos 57-A a 57-I na Lei n 9.504, de 1997, ficando assim permitida a propaganda eleitoral na internet, desde que gratuita.

Contudo, para o TSE, a lei não considera propaganda eleitoral antecipada se não houver pedido explícito de voto, menção a uma pretensa candidatura e a exaltação das qualidades pessoais dos pré-candidatos. Permite a participação de filiados a partidos ou de pré-candidatos em entrevistas, programas, encontros ou debates no rádio, na televisão e na internet, até com exposição de plataformas e projetos políticos. As emissoras de rádio e TV devem dar tratamento isonômico aos pré-candidatos.

Será considerada propaganda eleitoral antecipada a convocação por parte do presidente da República, dos presidentes da Câmara dos Deputados, do Senado Federal e do Supremo Tribunal Federal (STF), de redes de radiodifusão para divulgar atos que denotem propaganda política ou ataques a partidos e seus filiados ou instituições.

As normas eleitorais são de natureza cogente e obrigatória, e se constituem em leis federais ordinárias; leis complementares; Resoluções do TSE e TREs, com força de lei ordinária; e a Constituição Federal, ou seja, todos os atos e proibições devem estar amparados em lei. Poderão ainda ocorrer hipóteses às propagandas não previstas em lei

e estas deverão decorrer do princípio da legalidade e o da generalidade, ou seja, as normas eleitorais aplicam-se a todas as circunscrições eleitorais em todo o território nacional.

\section{PROPAGANDA ELEITORALANTECIPADA}

\section{I Conceito e elementos caracterizadores da propaganda extemporânea}

A propaganda eleitoral vem sendo distorcida por vários candidatos, coligações e partidos políticos que estão se sentindo livres para adotarem medidas que cada vez mais se configuram campanha eleitoral antecipada, de acordo com o estabelecido na legislação.

Segundo Rogério Takayassu Lemos, o termo extemporâneo reporta a tudo aquilo que está ou vem fora do tempo próprio, isto é, que não é próprio do tempo em que se faz ou sucede.

O principal motivo dessa ação reside no fato de que a multa pecuniária atualmente fixada pela legislação se revela irrisória ante os elevados recursos disponibilizados pelos candidatos, especialmente no que tange às eleições presidenciais, por exemplo:

Em 20 I 4, o TSE multou a presidente Dilma Rousseff em $\mathrm{R} \$ 25.000,00$ (vinte e cinco mil reais) por entender que ela fez propaganda eleitoral antecipada no 
pronunciamento em rede nacional de rádio e TV para marcar o Dia do Trabalho celebrado em $1^{\circ}$ de maio.

Naquele mesmo ano, novamente o Plenário do Tribunal Superior Eleitoral aplicou multa de $R \$ 7.500,00$ (sete mil e quinhentos reais) ao então ministro-chefe da Casa Civil, Aloizio Mercadante, por ter realizado propaganda eleitoral antecipada em favor da presidente Dilma Rousseff, candidata à reeleição para a Presidência da República. A irregularidade ocorreu durante entrevista coletiva convocada pelo ministro, no dia I 5 de junho de 2014 , sob o argumento de fazer um balanço sobre a Copa do Mundo.

A Resolução n 23.450, de 20 I 5, do Tribunal Superior Eleitoral é taxativa no sentido de que "a propaganda eleitoral somente será permitida a partir de 16 de agosto do ano da eleição".

$\bigcirc$ candidato que fizer propaganda eleitoral antecipada, além de estar sujeito ao pagamento de multa, pode vir a cometer abuso do poder econômico, porque estará realizando despesas de campanha antes da expedição do Cadastro Nacional de Pessoa Jurídica (CNPJ), da abertura de conta-corrente específica e da época permitida para a arrecadação de recursos, ou mesmo abuso dos meios de comunicação social (ROLLO, 2004).

Coneglian (2006) afirma que para uma mensagem ser considerada propaganda eleitoral antecipada deverá esta, quer no nível de denotação, quer no nível mais profundo de conotação, levar o eleitor a pensar na eleição. A mensagem deve estar se referindo à eleição, sob pena de se configurar mera promoção pessoal do futuro candidato, ou seja, quando se evidencia a intenção de revelar ao eleitorado, mesmo que de forma dissimulada, o cargo político almejado, ação política pretendida, além dos méritos habilitantes do candidato para o exercício da função.

$\bigcirc$ Tribunal Superior Eleitoral criou alguns elementos caracterizadores para a definição da propaganda eleitoral extemporânea, quais sejam: i) menção à candidatura; ii) menção ao futuro pleito eleitoral; iii) alusão à ação política a ser desenvolvida, ou razões que levem o eleitor a crer que o beneficiário ou autor da propaganda seja o mais indicado para o cargo.

Em várias ocasiões sobre o tema, o TSE se manifestou no sentido de que a propaganda eleitoral antecipada só se efetua quando esses três requisitos estão estabelecidos na mensagem, como exposto a seguir:

AGRAVO REGIMENTAL NO AGRAVO DE INSTRUMENTO. BOLETIM DISTRIBUÍDO POR MALA DIRETA A FILIADOS DO PARTIDO. PROPAGANDA EXTEMPORÂNEA. NÃO-CARACTERIZAÇÃO.

De acordo com a jurisprudência desta Corte, a propaganda eleitoral caracterizase por levar ao conhecimento geral, ainda que de forma dissimulada, a candidatura, a ação política ou as razões que levem a inferir que o beneficiário seja o mais apto para a função pública. Notícias das atividades do partido, sem qualquer conotação eleitoreira, não configuram propaganda eleitoral. Agravo desprovido. (AG n 5120, de I6/08/2005, Rel. Gilmar Ferreira Mendes). 
A jurisprudência do Tribunal Superior Eleitoral passou a admitir a caracterização da propaganda eleitoral antecipada a partir de referências indiretas, sendo certo que o trinômio 'candidato, pedido de voto e cargo pretendido' não é mais exigível, sendo suficiente a percepção de circunstâncias e peculiaridades associadas à eleição. Todavia, para a configuração do ilícito, forçosa a constatação de um mínimo de referências palpáveis a eleições, votos, candidaturas, projetos futuros, continuidade etc.

As práticas abusivas, via de regra, apresentam-se de forma oblíqua, sorrateiras, escudadas em atos ilícitos, levadas a efeito diretamente pelo interessado ou por terceiros a seu mando, ou de forma subliminar, induzindo o eleitor a optar por determinado candidato.

Dessa maneira é a jurisprudência do TRE-MG, senão vejamos:

"RECURSO. REPRESENTAÇÃO. ELEIÇÕES 20I0. PROPAGANDA ELEITORAL EXTEMPORÂNEA. ELEMENTOS CARACTERIZADORES. INTERNET. BLOG. MULTAAPLICADA NO PATAMAR MÍNIMO. I.Configurase propaganda eleitoral extemporânea quando presentes determinados requisitos como menção a pleito, nome ou número de partido político, apresentação de idéias e propostas, pedido de votos e exposição de razões que induzam a concluir que o beneficiário é o mais apto ao exercício de função pública. 2. A Constituiçã̃o da República, em seu art. $5^{\circ}$, IV, garante a liberdade de expressão, mas esta não é ilimitada, encontrando legítimo limite imposto pela própria Lei Maior em princípios e normas do ordenamento jurídico vigente. Especialmente com vistas a garantir o equilíbrio na disputa eleitoral, são impostas limitações à realização de propaganda eleitoral, que é proibida no período precedente aos três meses anteriores às eleições. Recurso a que se nega provimento." Ac. do TRE-MG na RP no 7I589I, de 20/09/2010, Rel. Juiz Octávio Augusto de Nigris Boccalini, publicado em Sessão.

"Recurso. Representação. Propaganda Eleitoral Extemporânea Eleições 2010. Imprensa Escrita. I. Propaganda eleitoral extemporânea subliminar, objetivando influenciar o eleitorado sobre concorrente mais qualificado pelo grande apoio que tem para o exercício da função pública, com a menção ao pleito vindouro e ao cargo que o beneficiário pretende se candidatar, o que deixa nítido, nas inserções contidas no periódico, o cunho eleitoreiro da publicação. 2. Divulgação de fotografias, nome em letras garrafais, cargo pretendido, bem como a menção às próximas eleições com intuito de gravar a futura candidatura do beneficiário na memória da sociedade, consubstanciam mecanismo de propaganda antecipada, apta a desequilibrar o pleito e a igualdade que rege o processo eleitoral. Recurso a que se nega provimento." Ac. do TRE-MG na RP n ${ }^{\circ}$ 58684I, de 06/08/2010, Rel. Juiz Octávio Augusto de Nigris Boccalini, publicado em Sessão.

Dessa forma, a fim de verificar a existência de propaganda subliminar, com propósito eleitoral, não se deve observar tão somente o texto desta, mas também outras circunstâncias, como imagens, fotografias, meios, número e alcance da divulgação. 
Para a jurisprudência do TSE, a propaganda eleitoral extemporânea em programa partidário se caracteriza pela promoção pessoal de filiado com finalidade eleitoral, especialmente quando pertencente a partido político diverso do responsável pela veiculação da publicidade. Senão vejamos:

"PROPAGANDA PARTIDÁRIA. ALEGAÇÃO DE DESVIO DE FINALIDADE. PROMOÇÃO PESSOAL. PROPAGANDA ELEITORAL EXTEMPORÂNEA. FILIADO. PARTIDO DIVERSO. CASSAÇÃO. TEMPO. BLOCO NACIONAL. PRELIMINARES. ILEGITIMIDADE PASSIVA. IMPOSSIBILIDADE JURÍDICA DO PEDIDO. INÉPCIA DAINICIAL. REJEIÇÃO. PROCEDÊNCIAPARCIAL. I. A propaganda eleitoral extemporânea em programa partidário se caracteriza pela promoção pessoal de filiado com finalidade eleitoral, especialmente quando pertencente a partido político diverso do responsável pela veiculação da publicidade. (...)." Ac. do TSE na RP no | 49357, de 09/08/20 I I , Rel. Min. Fátima I 0 Nancy Andrighi, publicado no DJE de I3/09/20 I I .

Assim, para a configuração de propaganda eleitoral extemporânea, exige-se a presença, ainda que de forma dissimulada, de menção a pleito futuro, pedido de votos ou exaltação das qualidades de futuro candidato, o que deve ser averiguado segundo critérios objetivos' (Ac. Do TSE no AgR-Al n. 2230-60.20 I 0.6.00.0000, de I³/20 I I, Min. Aldir Passarinho Júnior).

\subsection{Propaganda eleitoral antecipada realizada na propaganda partidária}

A propaganda partidária tem por finalidade divulgar, pelo rádio e pela televisão, os assuntos de interesse das agremiações partidárias, a fim de fortalecer o partido. Seu regulamento encontra-se escrito na Lei Orgânica dos Partidos Políticos nos artigos 45 a 49 da Lei n 9.096, de 1995. Sendo expressamente proibida a propaganda paga.

Todavia, essa modalidade de propaganda não será difundida, no horário a ela destinado no rádio e na televisão, no segundo semestre do ano da eleição, conforme estabelece o $\S 2^{\circ}$ do art. 36 da Lei $n^{\circ}$ 9.504, de 1997, porque visa à divulgação das ideias, propostas e ações desenvolvidas pelos partidos políticos, quando oportunamente já foram disponibilizados no primeiro semestre do ano da eleição aos partidos políticos para divulgação de suas propagandas, sendo, dessa forma, proibida a sua veiculação no segundo semestre do ano da eleição.

Costa (200 I ), ao comentar o artigo 36 da Lei n 9.504, de 1997, faz breve distinção entre propaganda partidária e eleitoral, afirmando o seguinte:

"A propaganda partidária é meio de divulgação da ideologia do partido político, sem vinculação a um pleito eleitoral específico, buscando granjear um maior número de adeptos e simpatizantes, ao passo que a propaganda eleitoral é meio de exposição de candidaturas a cargos eletivos, buscando conquistar o eleitorado e angariar votos em uma eleição". 
Segundo Aragão (2007), apesar de a lei ser bastante objetiva, frequentemente os partidos políticos se utilizam de seu espaço na mídia para promover futuros candidatos a cargos eletivos, divulgando a imagem e o nome dos pré-candidatos, conduta social deles, realização na vida política, contrariando expressamente o estabelecido na lei eleitoral.

Entende-se que a lei deseja que os partidos políticos usem o seu tempo nos meios de comunicação para realizarem políticas partidárias e discutir ações comunitárias, e não para produzirem políticas eleitorais. Dessa forma, se os partidos fazem campanha no horário gratuito, se aproveitam o tempo para fazerem propagandas eleitorais antecipadas, a lei está sendo desrespeitada, e os partidos devem ser punidos conforme a legislação.

O que se admite são as críticas ao governo atual e aos seus filiados pertencentes às agremiações partidárias adversárias, ainda que desabonadoras, mas que o debate político seja de interesse da comunidade.

Ajurisprudência do TSE se manifesta nesse sentido:

PROPAGANDA PARTIDÁRIA. ALEGAÇÃO DE DESVIO DE FINALIDADE. CRÍTICA. GOVERNO. FILIADO. PRÉ-CANDIDATO. PROPAGANDA ELEITORAL ANTECIPADA. INFRAÇÃO À LEI No 9.504/97. PEDIDO DE CASSAÇÃO DO PROGRAMA PREJUDICADO. PENA DE MULTA. IMPROCEDÊNCIADAREPRESENTAÇÃO.

I. A realização de críticas, ainda que desabonadoras, sobre a atuação de filiados e de governo sob a direção de agremiação adversária não caracteriza propaganda eleitoral subliminar e fora do período autorizado em lei, desde que não ultrapassem o limite da discussão de temas de interesse político comunitário, como o ocorrido na hipótese dos autos. 2. Improcedência da representação pela não-configuração de ofensa ao art. 36 da Lei das Eleições. (RP n 994, de 09/08/2007. Rel. Min. José Augusto Delgado).

PROPAGANDA PARTIDÁRIA. ALEGAÇÃO DE DESVIO DE FINALIDADE. CADEIA NACIONAL. OFENSA. PARTIDO POLÍTICO. PEDIDO. DIREITO DE RESPOSTA. INDEFERIMENTO. IMPROCEDÊNCIA DAREPRESENTAÇÃO.

Críticas contundentes com relação à atuação de filiados de partido político na condução do Executivo Federal, demonstrando o posicionamento do partido frente a temas político-comunitários, com base em conteúdo amplamente divulgado pelos meios de comunicação do País, não constituem ofensa às disposições legais sobre propaganda partidária. (RP, n 943, de 17/04/2007, Rel. Min. Francisco Cesar Asfor Rocha).

Muito embora seja clara a diferença entre as propagandas eleitorais e as partidárias, estas por várias vezes são desviadas de sua finalidade para ressaltar a figura, as ações e os méritos dos filiados que notoriamente serão ungidos candidatos nos próximos pleitos. Os desvios das finalidades das propagandas partidárias para exaltar as qualidades de 
notórios pré-candidatos configuram propagandas antecipadas, conforme anotado no precedente do TSE:

\begin{abstract}
CARACTERIZA PROPAGANDA ELEITORAL ANTECIPADA, AINDA QUE DE FORMA IMPLÍCITA, A VEICULAÇÃO DE PROPAGANDA PARTIDÁRIA PARA PROMOÇÃO DE FILIADO, NOTÓRIO PRÉ-CANDIDATO, COM CONOTAÇÃO ELEITORAL, QUE INDUZA O ELEITOR À CONCLUSÃO DE QUE SERIA O MAIS APTO PARA OCUPAR O CARGO QUE PLEITEIA, INCLUSIVE COM A DIVULGAÇÃO DE POSSÍVEIS LINHAS DE AÇÃO A SEREM IMPLEMENTADAS (R-RP N. I774I3, 10.08.2010, RELATOR MIN. JOELSONDIAS).

"PROPAGANDA PARTIDÁRIA. ALEGAÇÃO DE DESVIO DE FINALIDADE. PROMOÇÃO PESSOAL. PROPAGANDA ELEITORAL EXTEMPORÂNEA. FILIADO. PARTIDO DIVERSO. CASSAÇÃO. TEMPO. BLOCO NACIONAL. PRELIMINARES. ILEGITIMIDADE PASSIVA. IMPOSSIBILIDADE JURÍDICA DO PEDIDO. INÉPCIA DA INICIAL. REJEIÇÃO. PROCEDÊNCIA PARCIAL. I. A propaganda eleitoral extemporânea em programa partidário se caracteriza pela promoção pessoal de filiado com finalidade eleitoral, especialmente quando pertencente a partido político diverso do responsável pela veiculação da publicidade. (....." Ac. do TSE na RP n | 49357, de 09/08/20 I I, Rel. Min. Fátima IO Nancy Andrighi, publicado no DJE de 13/09/20 | | .
\end{abstract}

Para o TSE, propagandas eleitorais extemporâneas apresentam-se, via de regra, de forma implícita, induzindo, assim, os eleitores a optarem por determinados candidatos. Contudo na propaganda partidária essa prática caracteriza-se pela promoção pessoal de filiado com finalidade eleitoral, especialmente quando pertencente a partido político diverso do responsável pela veiculação da publicidade.

\title{
4 ABUSO DO PODER ECONÔMICO NA PROPAGANDA ELEITORAL EXTEMPORÂNEA
}

O abuso de poder econômico em matéria eleitoral se refere à utilização excessiva, antes ou durante a campanha eleitoral, de recursos materiais ou humanos que representem valor econômico, a fim de beneficiar candidato, partido ou coligação, afetando, assim, a normalidade e a legitimidade das eleições.

A ação corrosiva do abuso do poder, não raras vezes, conduz ao comando do executivo ou à ocupação de cadeiras nos parlamentos representantes, estes vinculados a interesses de grupos econômicos, dos quais se tornam reféns, em maior ou menor escala.

Segundo o art. 222 do Código Eleitoral Brasileiro, inválida é a votação quando viciada de falsidade, fraude, coação pela interferência do poder econômico ou do poder de autoridade, uso de meios vedados ou emprego de processo de propaganda ou captação de sufrágios vedados por lei - enfim, práticas que violem a normalidade, a 
regularidade, a equidade do processo eleitoral e a autonomia do eleitor.

O art. 237 do Código Eleitoral descreve que a interferência do poder econômico e o desvio ou abuso do poder de autoridade, em desfavor da liberdade do voto, serão coibidos e punidos. No art. 242, exige-se que toda propaganda eleitoral seja realizada em língua portuguesa.

Nas palavras de Vaz (1996), o abuso do poder econômico pode ser entendido, e deve ser comprovado, como excesso de gastos no processo eleitoral, pelo qual o candidato pode conquistar o mandato eletivo; é evidente que os gastos declarados pelo partido político, controlados e legalmente admitidos pela justiça eleitoral, não constituem abuso.

Ainda segundo o autor, esse abuso se caracteriza pelo mau uso, ou uso errado, excessivo ou injusto, como na própria definição etimológica do termo. Para que fique caracterizado o abuso de poder econômico, o candidato fará prevalecer a gastança exorbitante e descomedida, incidente pela utilização do poder econômico excessivo.

O uso do poder econômico é entendido como emprego de dinheiro mediante as mais diversas técnicas, que vão desde a ajuda financeira, pura e simples, a partidos e candidatos, até a manipulação da opinião pública, da vontade dos eleitores, por meio da propaganda política subliminar, com a aparência de propaganda meramente comercial.

No entendimento de Costa (2009, p. 358), o abuso do poder econômico consiste na vantagem dada a uma coletividade de eleitores, indeterminada ou determinável, beneficiando-os pessoalmente, ou não, com a finalidade de obter voto ao candidato. Para que a atuação deste ou alguém em seu beneficio seja considerada abusiva, é necessário que haja probabilidade de influenciar no resultado do pleito, ou seja, que haja relação de causalidade entre o ato praticado e a repercussão no resultado das eleições.

Na propaganda eleitoral antecipada, as autoridades públicas, empresas privadas, imprensa, entre outros que contribuem com dinheiro, material de divulgação, combustível e outros bens, agem como financiadores do pleito, contribuindo assim para uma das formas de caracterização do abuso do poder econômico.

Essa atitude causa desequilíbrio entre os candidatos e atinge os princípios fundamentais que regem o direito eleitoral. É fundamental que o poder econômico se mantenha neutro no processo eleitoral, que interfira apenas na medida do necessário, da previsão legal, fora disso, viola direito de igualdade dos partidos e candidatos e compromete a lisura e normalidade da eleição.

O voto direto e secreto, com igual valor para todos, consta do caput do artigo I 4 da Constituição Federal (CF), de 1988, enquanto os parágrafos $9^{\circ}$ e 10 do mesmo artigo demonstram preocupação em "[...] proteger a normalidade e legitimidade das eleições contra a influência do poder econômico [...]" e do Poder Político, prevendo que os mandatos podem ser cassados em caso de "[...] abuso de poder econômico, corrupção ou fraude". (NEISSER, 20|4).

No artigo 173, § 4, da CF, diz que "a lei reprimirá o abuso do poder econômico que vise à dominação do mercado, à eliminação da concorrência e ao aumento arbitrário 
dos lucros".

Nesse sentido, para que determinada despesa lícita possa ser enquadrada como abuso de poder econômico não apenas basta indicar sua realização, mas sim demonstrar que os respectivos pagamentos se deram de forma indevida, ou seja, por não ter sido eventualmente prestado o serviço que caracteriza a contraprestação, seja por eventual divergência do valor de mercado, ou ainda, por outra razão que demonstre a ilicitude do fato.

Qualquer partido político, coligação, candidato ou Ministério Público Eleitoral poderá representar ação de impugnação ao mandato eletivo à justiça eleitoral, diretamente ao corregedor-geral ou regional, relatando fatos e indicando provas, indícios e circunstâncias e pedir abertura de investigação judicial para apurar uso indevido ou abuso do poder econômico.

Para Milagres (20 I0), a propaganda eleitoral paga não é irrestrita; sofre limitações com vista a evitar maior desvirtuamento do processo eleitoral em favor daquele com maior capacidade econômica.

O art. 96 da Lei n 9.504, de 1997, é o procedimento subsidiário para prevenção e tutela do processo eleitoral. Restringe-se, basicamente, à prática de propaganda eleitoral ilícita, uma vez que as condutas vedadas - captação ou gasto ilícito de recursos de campanha - deverão ser objeto do procedimento sumário da Lei Complementar n 64, de 1990. (MILAGRES, 20 I0).

A imputação da responsabilidade pelo abuso demanda a prova da participação direta ou indireta do candidato. Segundo o TSE, para caracterização de conduta vedada pelo art. 4 I -A da Lei n 9.504, de 1997, é necessária prova da participação direta ou indireta do candidato no fato tido por ilegal, sendo, contudo, prescindível o pedido expresso de votos. Embora, em se tratando de abuso de poder, a responsabilidade seja objetiva, é despicienda a análise do elemento subjetivo.

Ministério Público Brasileiro tem o poder-dever de atuar no processo eleitoral, coibindo e reprimindo o abuso de poder, com fulcro no art. 127 da Constituição Federal, que lhe atribuiu a defesa da ordem jurídica e do regime democrático.

\section{I Sanções}

A principal penalidade conferida à propaganda eleitoral antecipada é a multa estabelecida no $\S 3^{\circ}$ do art. 36 da Lei n 9.504, de 1997, no valor de 20 a 50 mil UFIRs, ou equivalente ao custo da propaganda, se este for maior.

Entretanto, com as alterações da propaganda eleitoral promovidas pela Lei $n^{\circ}$ 13.165, de 2015, a propaganda realizada antes do prazo acima mencionado, denominada de propaganda antecipada, agora é punida com a aplicação de multa que varia de $\mathrm{R} \$ 5.000,00$ (cinco mil reais) a $\mathrm{R} \$ 25.000,00$ (vinte e cinco mil reais) apenas.

A multa referida no parágrafo anterior é aplicada ao responsável por sua publicação, e também ao beneficiário, caso seja comprovado o seu prévio conhecimento. Portanto, 
em qualquer situação, deve ser precedido o respectivo processo judicial, para que se venerem os princípios do contraditório e da ampla defesa expostos na CF, de 1988.

Ademais, com referência às sanções atribuídas pela legislação eleitoral na ocorrência de propaganda eleitoral extemporânea, também se aplica às emissoras de rádio e televisão a sanção contida no art. 56 da Lei n ${ }^{\circ}$ 9.504, de 1997, que se alude à suspensão, por 24 horas, da programação normal da emissora que deixar de cumprir as disposições da referida lei sobre a propaganda eleitoral.

Para a aplicação da multa cível eleitoral, o TSE exige o registro do pré-candidato como candidato devidamente registrado na Justiça Eleitoral a cargo eletivo, pois, do contrário, haveria punição por um fato jurídico que ainda não ocorrera. Exemplo: $\bigcirc$ fato de uma pessoa divulgar sua empresa ou produto em período eleitoral sem ainda estar filiado a Partido Político.

A punição do beneficiário da propaganda eleitoral antecipada exige a confirmação do seu prévio conhecimento, que pode ser inferido das circunstâncias do caso concreto. Ausente a prova do prévio conhecimento, o candidato beneficiário será notificado para retirar a propaganda irregular. Se o fizer no prazo de 48 horas, não será punido.

Do contrário, será responsabilizado, ainda que, em princípio, não tenha sido o autor da divulgação irregular. O poder de polícia, consistente na proibição da continuidade da veiculação das propagandas eleitorais antecipadas, será exercido por qualquer juiz eleitoral. As irregularidades constatadas deverão ser encaminhadas às procuradorias eleitorais, se necessário, e o caso proporá representações cabíveis para desencadear as punições legais.

No caso de propaganda eleitoral antecipada veiculada no horário gratuito da propaganda partidária, a sanção cominada é a cassação do direito de transmissão a que faria jus o partido, no semestre subsequente ao da veiculação da propaganda, conforme consigna o art. 45, § $2^{\circ}$, da Lei n 9.096, de 1995, além da multa estabelecida no $\S 3^{\circ} \mathrm{da}$ Lei das Eleições, entendimento este já consagrado na jurisprudência do TSE, como se pode observar da seguinte decisão:

Representação. Art. 36, § 30, da Lei no 9.504/97. Propaganda eleitoral extemporânea. Propaganda partidária. Decisão regional. Procedência. Agravo de instrumento. Decisão monocrática. Negativa de seguimento. Agravo regimental. Fundamentos não impugnados. Possibilidade. Aplicação. Sanção pecuniária. Ausência. Prequestionamento. Pretensão. Reexame. Fatos e provas. Impossibilidade. Dissenso jurisprudencial. Não configuração.

I. $\bigcirc$ agravo regimental não pode constituir mera reiteração das razões do recurso denegado, devendo atacar especificamente os fundamentos da decisão agravada.

2. É possível a aplicação de multa, com base no $\S 3^{\circ}$ do art. 36 da Lei $n^{\circ}$ 9.504/1997, em sede de representação, ainda que a propaganda eleitoral antecipada tenha ocorrido na propaganda partidária.

3. A ausência de prequestionamento de determinada matéria impede o seu 
conhecimento na instância especial, incidindo as Súmulas nos 282 e 356 do Supremo Tribunal Federal.

4. Para afastar a conclusão da Corte Regional Eleitoral que, no caso concreto, entendeu configurada a propaganda eleitoral antecipada ocorrida na propaganda partidária, seria necessário o reexame de fatos e provas, o que não é possível em sede de recurso especial por óbice da Súmula n .279 do Supremo Tribunal Federal.

5. A mera transcrição de ementas não é suficiente para a configuração do dissenso jurisprudencial. Agravo regimental desprovido. (AG n 7634, de 04/09/2007. Rel. Min. Carlos Eduardo Caputo Bastos).

PROPAGANDA PARTIDÁRIA. ALEGAÇÃO DE DESVIO DE FINALIDADE. EXCLUSIVA PROMOÇÃO PESSOAL. FILIADO. PRÉ-CANDIDATO. PROPAGANDAELEITORALANTECIPADA. PRELIMINARES.

As sanções pela prática de abuso de poder político e econômico estão previstas no inciso XIV do art. 22 da Lei Complementarn | 35, de 2010 :

\begin{abstract}
XIV - julgada procedente a representação, ainda que após a proclamação dos eleitos, o Tribunal declarará a inelegibilidade do representado e de quantos hajam contribuído para a prática do ato, cominando-lhes sanção de inelegibilidade para as eleições a se realizarem nos 8 (oito) anos subsequentes à eleição em que se verificou, além da cassação do registro ou diploma do candidato diretamente beneficiado pela interferência do poder econômico ou pelo desvio ou abuso do poder de autoridade ou dos meios de comunicação, determinando a remessa dos autos ao Ministério Público Eleitoral, para instauração de processo disciplinar, se for o caso, e de ação penal, ordenando quaisquer outras providências que a espécie comportar;
\end{abstract}

Segundo Rebouças (2012, p. 8), o art. 14, § 10, da Constituição prevê a ação de impugnação do mandato eletivo ante a Justiça Eleitoral no prazo de quinze dias contados da diplomação, instruída a ação com provas de abuso do poder econômico, corrupção ou fraude. Essa ação eleitoral, a única de cunho eminentemente constitucional, configura-se numa verdadeira ação anulatória de mandato eletivo quando constatado abuso de poder econômico, corrupção ou fraude.

De acordo com Neisser (2014, p. 83), o Código Eleitoral aponta três crimes relacionados ao controle formal da propaganda eleitoral. $\bigcirc$ artigo 334 prevê pena de detenção de 6 meses a I ano e cassação do registro, quando o candidato responsável "[...] utilizar organização comercial de vendas, distribuição de mercadorias, prêmios e sorteios para propaganda ou aliciamento de eleitores". Refere-se aos meios de propaganda vetados pela legislação, inserindo-se no âmbito formal de controle.

O artigo 335 prevê pena de detenção de 3 a 6 meses e multa para realização de propaganda eleitoral em língua estrangeira. Por fim, o artigo 337 descreve como crime a participação de estrangeiro ou brasileiro com direitos políticos suspensos em atividades 
partidárias, até mesmo em comícios e outros atos de propaganda eleitoral.

Desse modo, as sanções impostas aos responsáveis pelo desrespeito à legislação eleitoral em vigor exercem a função de coibir tal prática, preservando a lisura do processo eleitoral.

\section{CONCLUSÃO}

Oabuso do poder econômico na propaganda eleitoral extemporânea representa um encalce para o exercício pleno do Estado Democrático de Direito. Considerandose o prazo legal da propaganda eleitoral, qual seja, I 5 de agosto do ano da eleição, e o período em que esta não é permitida, a veiculação de propaganda em data e de forma divergente da regulamentada pela legislação eleitoral configura propaganda extemporânea, em face do candidato, partido político ou coligação.

A influência do poder aquisitivo dos candidatos nas campanhas eleitorais persuade os eleitores pelos meios de comunicação, sendo que uma das principais formas caracterizadas desse poder é propaganda eleitoral antecipada. Dessa forma, tal abuso do poder fere os princípios da isonomia, moralidade e legalidade do processo eleitoral.

Verifica-se a despreocupação de vários candidatos ao cumprimento das normas relativas à propaganda eleitoral extemporânea, notadamente diante do valor pouco expressivo das multas cominadas a título de sanção. É aconselhável, portanto, uma revisão dos valores das multas, de forma a torná-las mais intimidadoras.

O controle realizado pela justiça eleitoral sobre a propaganda eleitoral antecipada visa coibir tal prática e garantir a igualdade de oportunidades entre os candidatos, impedindo, assim, a criação de desigualdade entre estes, além de evitar a camuflagem ao abuso do poder econômico.

Caso ocorra violação à legislação que regulamenta a propaganda eleitoral, notadamente no que se refere à época de sua viabilidade, é cabível a aplicação de sanção administrativo-eleitoral pertinente, relacionada à prática de propaganda extemporânea pelo candidato que a patrocinou ou que diretamente se beneficia com esta.

A população está cada vez mais atuante no cenário político, e o fato de participar dos debates lhe permite ficar mais atenta ao desempenho de seus representantes. Por isso, a utilização excessiva do poder econômico no pleito eleitoral, pela propaganda antecipada, constitui-se de ato condenável não só pela legislação eleitoral, mas também pela sociedade que está mais difícil de ser ludibriada com campanhas publicitárias fantasiosas.

A busca de um processo eleitoral mais justo e consentâneo com a vontade popular demanda aprimoramento da ordem jurídica, ampliando-se, sobretudo, os mecanismos de controle, fiscalização, punição dos infratores.

Após essas considerações, com base no estudo doutrinário e na legislação em vigor, conclui-se que o poder econômico deve permanecer neutro, evitando, dessa forma, a violação do direito de igualdade entre os partidos e candidatos. $\bigcirc$ direito eleitoral, na 
medida de sua dinamicidade, mais especificamente no que tange às posições do Tribunal Superior Eleitoral, exige do operador do direito mais cautela com relação aos novos entendimentos dos tribunais e à nova legislação inserida em nosso ordenamento jurídico.

\section{REFERÊNCIAS}

ARAGÃO, Luara Nobre. Propaganda eleitoral antecipada: aspectos doutrinários e jurisprudenciais. 2007.66p. Trabalho de Conclusão de Curso (Especialista em Direito e Processo Eleitoral) - Universidade Vale do Acaraú - UVA. Fortaleza-CE.

BRASIL. Código eleitoral. Lei n. 4.737, de 15 de Julho de 1965. Disponível em: <http://www.planalto.gov.br/ccivil_03/leis/L4737.htm>. Acesso em I 5 de outubro 2015

BRASIL. Constituição da República Federativa do Brasil de 1988. Disponível em: <http://www.planalto.gov.br/ccivil_03/Constituicao/Constituiçao.htm>. Acesso em 15 outubro 2014.

BRASIL. Lei das eleições. Lei n. 9.504, de 30 de setembro de 1997. Disponível em: < http://www.planalto.gov.br/ccivil_03/leis/19504.htm>. Acesso em I 2 de agosto 20 I 4.

BRASIL. Lei $n^{\circ}$. 13.165, de 29 de setembro de 2015. Disponível em: <http://www.planalto.gov.br/ccivil_03/_ato20 I5-20 I8/20 I5/lei/l 3 I65.htm>. Acesso em 15 dezembro 2015.

BRASIL. Lei orgânica dos partidos políticos, Lei $n^{\circ}$. 9.096, de 19 de setembro de 1995. Disponível em:<http://www.planalto.gov.br/ccivil 03/leis/19096.htm>. Acesso em 2 outubro 2014.

BRASIL. Tribunal Superior eleitoral. Resolução 23.450, de 10 de Novembro de 20 I 5.Disponívelem: < http://chimera.tse.jus.br/legislacaotse/res/20 I 5/RES2345020 I 5.htm > . Acesso em 2 de dezembro 2015.

BRASIL. Superior Tribunal Eleitoral. Respe n 6 | 83, De 17-02-2000. Rel. José Eduardo Rangel De A I ckmin. Disponível e m : <http://www.jusbrasil.com.br/diarios/79778665/tre-se- | 0- | |-20 | 4-pg- | 3in>. Acesso em 10 de novembro 2015. 
BRASIL. Supremo Tribunal Federal.Respe n 15732, De 15-04-1999, Rel. José EduardoRangelDeAlckmin.Disponívelem: <http://www.jusbrasil.com.br/jurisprudenci a/busca?q=RESPE + n\%C2\%BA+ I 5732>. Acesso em 10 de novembro 2015.

BRASIL. Supremo Tribunal Federal.ADI n. ${ }^{\circ}, 3.74$ I-DF. Rel. Min. Ricardo Lewandowski.Disponívelem: < http://www .tresc.jus.br/site/fileadmin/arquivos/legjuris p/outros/adi_374 I - I.pdf > .Acesso em 10 de novembro 2015.

BRASIL. Tribunal Superior Eleitoral. AG n 5120, de 16/08/2005, Rel. Gilmar FerreiraMendes.Disponívelem: < http://www.jusbrasil.com.br/busca?q=]+ propagand $\mathrm{a}+$ antecipada + veiculada + em + programa + partid\%C3\%A I rio\&c $=>$. Acesso em I I de novembro 20 I 5 .

BRASIL. Tribunal Superior Eleitoral. RP, no 943, de 17/04/2007, Rel. Min. Francisco Cesar Asfor Rocha. Disponível em: <http://www.jusbrasil.com.br/jurisprudencia/busca?q=e +n\%C3\%A3o + por + desvio +de +finalidade +de + propag anda + partid\%C3\%A I ria $>$. Acesso em II de novembro 2015.

BRASIL. Tribunal Superior Eleitoral. R-RP n. 177413, j.j. 10.08.2010, Rel. Min. Joelson Dias. Disponível em: <http://www.jusbrasil.com.br/diarios/786785 I 6/tre-mg22-|0-20|4-pg-|5>. Acesso em 17 de dezembro 2015.

BRASIL. Tribunal Superior Eleitoral. Propaganda Eleitoral. Eleições 20 I 6: propaganda eleitoral de candidatos deve respeitar restrições da legislação. Disponível em: < http://www.tse.jus.br/imprensa/noticias-tse/20 I 6/Maio/eleicoes-20 I 6propaganda-eleitoral-de-candidatos-deve-respeitar-restricoes-da-legislacao >. Acesso em 18 de agosto 2016.

CÂNDIDO, Joel José. Direito eleitoral brasileiro. 6. ed. rev. e atual. São Paulo: Edipro, 1996.

CONEGLIAN, Olivar. Propaganda eleitoral. 8. ed. Curitiba: Juruá, 2006.

COSTA, Nelson Nery. Curso de ciências políticas. Rio de Janeiro: Forense, 200 I .

COSTA, Adriana Soares da. Direito eleitoral. 8. ed. rev. atual e ampl. Rio de Janeiro: Lumen Juris, 2009.

GOMES, José Jairo. Direito eleitoral. 6. ed. rev. atual e ampl. São Paulo: Atlas, 201 I.

GOMES, José Jairo. Direito eleitoral. 8. ed. São Paulo: Atlas, 2012. 
LEMOS, Rogério Takayassu. Progaganda Eleitoral Extemporânea: A propaganda eleitoral extemporânea e a liberdade de expressão. Revista Paraná Eleitoral, n. 7I, 2009. Disponível: http://www.justicaeleitoral.jus.br/arquivos/tre-pr-revista-paranaeleitoral-n07 I-2009-rogerio-takayassu-lemos. Acesso em I 2 de agosto de 2016.

MILAGRES, Marcelo de Oliveira. Abuso de poder no processo eleitoral. Revista Brasileira de Estudos Políticos, Belo Horizonte, n. I00, p. I 55- I 72, jan./jun. 2010.

MOREIRA, Ricardo. Sistema eleitoral brasileiro: evolução histórica. Jus Navigandi, Disponível em: <http://jus2.uol.com.br/doutrina/texto.asp?id=3468>. Acesso em 22 setembro 2014.

PINHO, Cristiano Vilela de; CAETANO, Flávio Crocce Caetano; GOMES, Wilton Luis da Silva. Elementos de direito eleitoral. São Paulo: Suplegraf, 2010.

RAMAYANA, Marcos. Direito Eleitoral. 8. ed. rev., ampliada e atualizada. Niterói: Impetus, 2008.

ROLLO, Arthur Luis Mendonça. Formas de propaganda eleitoral permitidas e proibidas. Propaganda institucional-vedação nos três meses anteriores ao pleito. In: Propaganda Eleitoral Teoria e Prática. 2. ed. São Paulo: Revista dos Tribunais, 2004.

VAZ, Orlando. Impugnação de mandato eletivo. In: VELOSO, Carlos Mário da Silva;

ROCHA, Cármen Lúcia Antunes. Direito eleitoral. Belo Horizonte: Del Rey, I 996, p. 349.

Recebido em:29/02/2016

Aprovado em: 20/06/2016 